
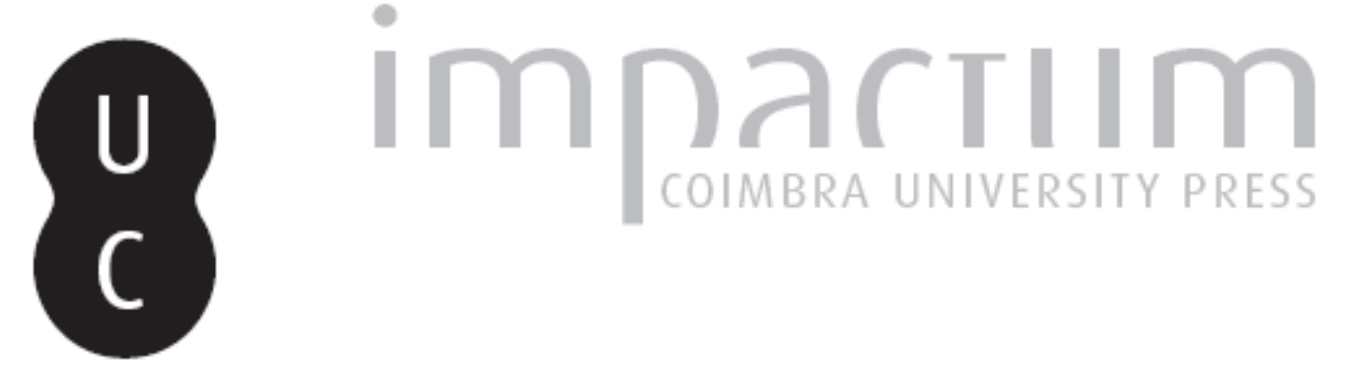

\title{
O tratamento jurídico dos complementos alimentares no contexto da dopagem desportiva: análise à luz de políticas públicas internacionais e da Espanha
}

Autor(es): $\quad$ Atienza Macías, Elena; Myszczuk, Ana Paula

Publicado por: $\quad$ Centro de Informação Europe Direct de Aveiro; Centro de Estudos
Interdisciplinares do Século XX

URL

persistente:

DOI: $\quad$ DOI:http://dx.doi.org/10.14195/1647-6336_14_10

Accessed : $\quad$ 26-Apr-2023 11:34:22

A navegação consulta e descarregamento dos títulos inseridos nas Bibliotecas Digitais UC Digitalis, UC Pombalina e UC Impactum, pressupõem a aceitação plena e sem reservas dos Termos e Condições de Uso destas Bibliotecas Digitais, disponíveis em https://digitalis.uc.pt/pt-pt/termos.

Conforme exposto nos referidos Termos e Condições de Uso, o descarregamento de títulos de acesso restrito requer uma licença válida de autorização devendo o utilizador aceder ao(s) documento(s) a partir de um endereço de IP da instituição detentora da supramencionada licença.

Ao utilizador é apenas permitido o descarregamento para uso pessoal, pelo que o emprego do(s) título(s) descarregado(s) para outro fim, designadamente comercial, carece de autorização do respetivo autor ou editor da obra.

Na medida em que todas as obras da UC Digitalis se encontram protegidas pelo Código do Direito de Autor e Direitos Conexos e demais legislação aplicável, toda a cópia, parcial ou total, deste documento, nos casos em que é legalmente admitida, deverá conter ou fazer-se acompanhar por este aviso. 
DEBATER

A EUROPA

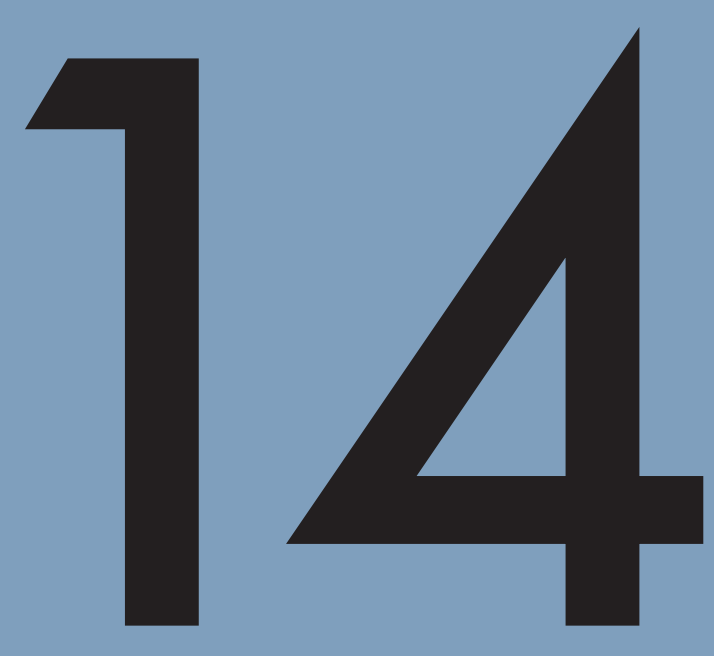

jan-jun 2016

EUROPA, FARMÁCIA, MEDICAMENTOS

EUROPE, PHARMACY, MEDICINES 


\title{
O tratamento jurídico dos complementos alimentares no contexto da dopagem desportiva: análise à luz de políticas públicas internacionais e da Espanha
}

\author{
Elena Atienza Macías \\ Investigadora da Universidade do Deusto \\ Cátedra Interuniversitária de Direito e Genoma Humano, Universidade do Deusto - País Basco, Espanha \\ E-mail: elena.atienza@deusto.es \\ Ana Paula Myszczuk \\ Professora do Programa de Pós-graduação em Planejamento e Governança Pública \\ Universidade Tecnológica Federal do Paraná (UTFPR), Brasil \\ E-mail: anapaulamy@yahoo.com.br
}

\section{Resumo}

O artigo tem como problemática discutir as mudanças nas políticas públicas dos organismos internacionais e nacionais (Espanha), que mudaram a regulação acerca do uso de complementos alimentares, substâncias proibidas no esporte e dopagem. Centra-se nos complementos alimentares e as consequências, para os desportistas, do uso voluntário ou involuntário de substâncias proibidas e a detecção disso em um teste antidopagem. O objetivo do artigo é analisar a regulação desportiva sobre dopagem e o uso de complementos alimentares e a responsabilização objetiva dos desportistas, quando da positivação para substâncias proibidas em teste antidopagem. Para realizar essa análise é utilizado o método bibliográfico e documental, além do estudo de caso ("Caso Contador"). Entre as principais considerações, se verifica: 1. Uma grande porcentagem de resultados positivos em controlem de dopagem é devida a existência de contaminação de suplementos alimentares com substâncias incluídas na "Lista de substâncias e métodos proibidos no esporte". 2. Um dos fatores de risco principais dos complementos alimentares em relação à positivação de amostras por dopagem é o fato de que muitos desportistas estão utilizando-os com 
desconhecimento de seus efeitos secundários e das doses recomendadas do produto. 3. A AEPSAD assessora pró-ativamente os desportistas e organizações desportivas espanholas sobre o problema da dopagem involuntária. Para esse fim se vale da ferramenta "selos de qualidade", que concede certificação de complementos alimentares desenvolvidos e avaliados em conjunto com a Organização Nacional Antidopagem, permitindo ao desportista efetuar uma compra segura de complementos. 4. Para a AMA a educação dos desportistas e seu entorno é um pilar fundamental na luta contra a dopagem. 5. O Código Mundial Antidopagem de 2015 enfatiza a necessidade de implementação de programas educativos baseados na prevenção, com o objetivo de que os desportistas e o pessoal de apoio adquiram conhecimentos específicos nas áreas dos riscos relacionados com o uso de complementos alimentares.

Palavras-chave: Direito Desportivo; Dopagem desportiva; Complementos Alimentares; Ética e Esporte; Caso Contador

\begin{abstract}
In the field of doping suppression, there is a tenuous dividing line between food supplements and drugs. In this regard, it is especially alarming that such supplements may contain substances that are potentially toxic to athletes, components that are prohibited under antidoping regulations either by themselves, as prohormones or as metabolic products. In fact, a large percentage of positive results in doping controls are due to the presence in, or contamination of supplements with substances listed in the well-known "Prohibited Substances and Methods List". On the other hand, we should point out that it is not only highlevel athletes who use this type of substance to compete more effectively: their use is widespread in certain social activities, such growing muscles or losing weight. In these cases, we often find people who do not practice a sport purely for "leisure" but rather, to achieve certain ideals of beauty through the design of their body shapes, such as bodybuildingpractices specifically aimed at the cultivation of the body, in gyms, fitness rooms and the like. Not only are these substances being used more widely, they are easy to obtain and there may be a lack of security and quality control. In this paper we intend to set forth, briefly but rigorously, the mix of legal issues around the extended use of (incorrectly) so-called "food supplements", trying to express in full the complex inventory of problems arising from the lack of ad hoc regulation in the field of doping in sport.
\end{abstract}

Keywords: Sports Law; Doping in sport; Food supplements; Sports Ethics; Case Law 


\section{Introdução}

O esporte é um dos negócios mais rentáveis do século XXI ${ }^{\mathbf{1}}$. Bilhões de dólares são anualmente ganhos com os eventos desportivos e centenas de pessoas devem suas carreiras e renda a este setor. Tendo em vista a magnitude desse empreendimento, busca-se a segurança de que, nas competições, os desportistas estejam se utilizando apenas de seus esforços e talento na busca de ser o melhor em sua categoria, sem que métodos ilegais possam interferir no resultado, seja para beneficiar uns ou para prejudicar outros.

Acrescente-se a esse fato o de que, a cada ano, mais e mais pessoas buscam melhorar a sua condição de saúde por meio da prática de uma atividade física e a introdução de uma dieta saudável e, muitas vezes, com o uso de complementos alimentares para obter melhores resultados.

Nesse contexto, a possibilidade da dopagem é um fantasma que ronda constantemente o esporte, os desportistas e os praticantes de atividades físicas. Novas substâncias são inventadas a cada ano, tornando-se cada vez mais difíceis de detectar e, quase sempre, devastadoras para a saúde dos desportistas. Seja o uso intencional, seja o involuntário, atualmente as autoridades desportivas, médicos, nutricionais e profissionais da educação física, entre outros, são confrontados com inúmeros questionamentos médicos, éticos e jurídicos, na sua atuação diária.

Desde a busca por substâncias dopantes, por drogas que mascarem a presença de outras drogas, de fármacos, remédios ou complementos alimentares que melhorem a condição física dos atletas ou outros desportistas, até a análise das consequências do uso desses produtos para a saúde atletas, desportistas e a população em geral, o uso consciente e sustentável desses produtos se impõe. E, mais importante do que resultados, prêmios e lucros, nos dias atuais o que deve pautar a atuação de todos os profissionais é a preservação da saúde dos desportistas.

É o ser humano, enquanto valor fundamental, sua saúde e integridade física e mental quem deve pautar a atuação profissional própria e dos envolvidos nas atividades desportivas. E, nesse sentido, as autoridades devem agir de forma integrada para possibilitar que o esporte continue sendo o negócio rentável que é; sem deixar de ter em mente que a vida é o valor mais importante nesse jogo.

$\mathrm{Na}$ esteira do que foi exposto, o presente artigo tem como problemática discutir as mudanças nas políticas públicas dos organismos internacionais e nacionais, centrando-se no

\footnotetext{
${ }^{1}$ O presente artigo foi produzido no Programa para a Formação Pessoal de Pesquisadores da Universidade do Deusto, do qual a autora Elena Atienza Macia faz parte.
} 
caso espanhol, que se reflete nas mudanças na regulação acerca do uso de substâncias proibidas no esporte. Dentre as principais inquietações que essa problemática traz está a questão do uso de complementos alimentares, que ficam num limbo entre o alimento e o medicamento, acabando por cair num vazio de regulação, gerando uma série de questionamentos médicos, éticos e jurídicos. Nesse sentido, as autoridades desportivas tem apertado o cerco contra o uso, por desportistas, de complementos do qual não se saiba a composição, que não tenham clareza na rotulagem ou que possam estar contaminados com substâncias proibidas. Isso, sem falar, nas consequências desse para a saúde do desportista. Portanto, o artigo se centra em analisar a regulação internacional e espanhola sobre o tema dos complementos alimentares no esporte e as consequências, para os desportistas, do uso voluntário ou involuntário de substâncias proibidas e a detecção disso em um teste antidopagem. Assim, o objetivo é analisar as referidas políticas públicas, que resultaram na modificação da regulação desportiva sobre dopagem e o uso de complementos alimentares e na responsabilização objetiva dos desportistas, quando da positivação para substâncias proibidas em teste antidopagem.

Para realizar essa análise é utilizado o método bibliográfico e documental, além do estudo de caso. No que se refere ao método bibliográfico, o artigo apresenta, no seu decorrer, um overview dos principais escritos sobre o tema nos últimos anos. Na questão documental, são analisados documentos internacionais e espanhóis, como o Código Mundial Antidopagem, Lei Orgânica 03/3013, de 20 de julho, para a Proteção da Saúde do Desportista e da Luta contra a Dopagem na Atividade Desportiva, (Espanha) e a regulação que criou a "Agência Espanhola de Proteção da Saúde no Esporte" (AEPSAD). Por fim, o artigo realiza o estudo do chamado "Caso Contador", para demonstrar a mudança paradigmática que houve no entendimento de que existe responsabilidade objetiva do atleta que ingere complementos alimentares, quando da positivação de uma substância proibida em um teste antidopagem.

\section{O Estado da arte}

No terreno da repressão a dopagem existe uma tênue linha divisória entre os complementos alimentícios e as substâncias proibidas. Nesse sentido, é especialmente alarmante que os chamados complementos possam conter substâncias potencialmente nocivas e, no caso concreto dos desportistas, componentes que são proibidos pelas regras antidopagem - seja por essas mesmas, como os pró-hormônios ou como produtos do metabolismo. Com efeito, uma grande porcentagem de resultados positivos, no controle de dopagem, é 
decorrente da presença ou da contaminação de complementos alimentares com substâncias incluídas na chamada "lista de substâncias e métodos proibidos no esporte".

De outro lado, há que se levar em consideração que não só o desportista de alto nível utiliza esse tipo de substância para competir mais eficazmente, mas seu uso está amplamente verificado a atividades sociais, como aquelas para fazer crescer músculos ou emagrecer. Nesse cenário, em não poucas ocasiões, podemos nos encontrar em face de pessoas que, em última instância, não praticam um determinado esporte por recreio, mas para alcançar certos ideais de beleza, por meio do desenho das formas de seu corpo - como no denominado "bodybuilding" -, práticas dirigidas especificamente ao cultivo do corpo em academias fitnesss ou similares. $\mathrm{Na}$ análise da ação/uso dessas substâncias se pode acrescentar tanto a questão da facilidade de acesso a sua obtenção, como a possibilidade de falta de segurança e supervisão da qualidade das mesmas.

Em se tendo em vista o uso dessas substâncias, o artigo pretende-se expor brevemente, mas de forma rigorosa, o amálgama de questões jurídicas que o uso estendido dos mal chamados "complementos alimentares" suscitam, procurando dar conta do complexo inventário de problemas derivados da carência de uma regulação ad hoc no âmbito da dopagem no esporte ${ }^{2}$.

\section{Difusão da dopagem: o impacto na saúde}

\subsection{A oportunidade do tema}

A preocupação do legislador com a regulação das questões relativas à dopagem no esporte não um tema trivial, mas reflexo da preocupação que nasce na própria sociedade uma vez que o Direito e a lei sempre dão suporte à sociedade, no brocardo, "Ubi ius,ibi societas"- e, mais especificamente, no próprio mundo desportivo. Tudo isso tem sua razão de ser no irrefutável fato de que o fenômeno desportivo adquiriu, nas últimas décadas, uma relevância de dimensões extraordinárias e que se projetam nos mais variados terrenos.

\footnotetext{
${ }^{2}$ Sobre o tema é necessário remeter-se a fundamentos doutrinários, tais como: ARJONA PÉREZ, David "Suplementos Alimenticios Deportivos, ¿pueden hacer al deportista que ‘dé positivo'?”, Alto rendimiento: ciencia deportiva, entrenamiento y fitness, Núm. 22, Junho 2011, disponível em: http://altorendimiento.com/nutricion-deportiva-suplementos-2/ [Última consulta: 15 de Julho de 2015] o CANTERO MARTÍNEZ, Josefa, "Política antidopaje y sistema nacional de salud: el nuevo marco de conexiones establecido en la Ley Orgánica 7/2006, de 21 de noviembre", Revista Aranzadi de Derecho de Deporte y Entretenimiento, Núm. 23, 2008, pp. 54-55. Já advertiam alguns estudos patrocinados pelo Comitê Olímpico Internacional (COI) que na Espanha cerca de 13,8\% dos complementos que são vendidos aos desportistas poderiam conter produtos anabolizantes que não estão indicados na embalagem, ocasionando, eventualmente, um resultado positivo de dopagem. É isso o que constata CASAJÚS MALLÉN, José Antonio Dopaje, salud y deporte. Información Terapéutica del Sistema Nacional de Salud. 29:1 (2005) 7.
} 
Resulta significativo que, dentre os muitos campos que precisam de interdisciplinaridade e que estão ligados as mais palpitante atualidades, está o esporte e, em particular, os riscos que crescentemente ameaçam essa atividade. Entre esses perigos se sobressai a dopagem - tanto pela grave ameaça que representa para a saúde pública e individual dos desportistas profissionais e amadores, como pela desvirtualização da competição - cujos casos mais notórios transcendem a opinião pública. Certamente, nos últimos anos essa problemática vem adquirindo protagonismo, tendo em vista a espiral crescente de casos célebres com o de Lance Armstrong- o mais famoso caso de dopagem positiva no mundo do esporte - ou o do ciclista Alberto Contador ${ }^{3}$, em nível espanhol, que se tornou o arquétipo da "teoria da contaminação alimentar".

Contudo, quando se adentra na análise da dopagem, considerações sumamente delicadas e que transcendem a problemas graves e complexos devem ser realizadas, em uma perspectiva decididamente multidisciplinar e, por conseguinte, impregnada de reflexões de diversas naturezas. A perspectiva econômica, política e midiática são as que mais saltam à luz, mas devem ser consideradas, também, as que versam especialmente sobre o escopo desse artigo, dizendo respeito à órbita jurídico-sanitária, uma vez que o esporte é o espaço onde se evidenciam as relações na tríade "alimentação-esporte-saúde" com maior intensidade e conflitualidade.

Não se pode esquecer que a legislação determina que qualquer procedimento que se relacione ao estado de saúde do desportista deve ser analisado com o objetivo de proteger sua saúde, integridade física, psíquica e genética; e não para dar causa a novos fatores de opressão. Nesse contexto, a proteção de sua intimidade é primordial e encontra três fundamentos principais:

a) É entendida como o reduto da personalidade, ou seja, a esfera da intimidade que fica direta e exclusivamente reservada ao próprio interessado; como a manifestação de confidencialidade compartilhada para aqueles aspectos da intimidade que, por prescrição legal ou pela natureza das relações interindividuais ou sociais, facultam o acesso a terceiros que estão obrigados, por lei, a manter sua confidencialidade e como proteção ao processamento de dados.

b) É o indivíduo quem deve decidir a quem revela, quando e com que extensão, ficando proibida a transmissão a terceiros da informação obtida através de análise

\footnotetext{
${ }^{3}$ A doutrina ecoou esse caso tão notório: AMORÓs MARTínEZ, Agustín - El caso Contador: una lectura reposada a la luz del borrador del CSD sobre el proyecto de ley orgánica de lucha contra el dopaje. Revista Aranzadi de Derecho de Deporte y Entretenimiento. 36 (2012) 457-492.
} 
das amostras sem o expresso consentimento do interessado ou de seu representante legal.

c) É de primordial importância frisar que qualquer acesso as amostras seja precedida do consentimento prévio, livre e informado do(s) desportista(es) envolvido(s) na pesquisa. A necessidade de se obter deste tal permissão deriva do princípio da autonomia da vontade do sujeito e é o requisito que legitima a atividade realizada ${ }^{4}$.

\subsection{Algumas pinceladas sobre o panorama normativo espanhol e internacional}

Nos últimos anos assiste-se perplexamente a incessantes mudanças na regulação da dopagem na prática desportiva; variação das regras de jogo que demonstram que o Direito Desportivo não apenas ganhou autonomia e identidade próprias como disciplina jurídica, mas que o próprio fenômeno da dopagem seja um campo hábil para uma exaustiva análise jurídica diferenciada e independente.

De fato, 2015 foi um ano especialmente profícuo para o estudo das questões jurídicas que a dopagem desencadeia, destacando-se a entrada em vigor, em janeiro de 2015, da terceira versão ${ }^{5}$ do Código Mundial Antidopagem (CMA) - projeto que foi iniciado na World Antidoping Agency (mais conhecida como WADA) ou Agência Mundial Antidopagem (AMA), no final de 2011, com um intenso processo de consultas aos stakeholders envolvidos na luta contra este estigma no esporte -, cujo cumprimento garantirá avanços indispensáveis na erradicação da dopagem ${ }^{6}$.

Paralelamente a Espanha empreendeu o pertinente caminho de adaptação de sua regulação a esse novo Código mundial, implantando um modelo legislativo de, relativamente recente, surgimento. Nesse sentido, em 2013, a Espanha desenvolveu e aprovou a Lei

\footnotetext{
${ }^{4}$ Ver: MYSZCZUK, Ana Paula. MEIRELLES, Jussara Maria Leal de. Testes genéticos, Eugenia e contrato do trabalho: Análise à luz da Declaração Universal Dos Direitos Humanos e Do Genoma Humano e da Constituição Federal De 1988. Trabalho publicado nos Anais do XVIII Congresso Nacional do CONPEDI, realizado em São Paulo - SP nos dias 04, 05, 06 e 07 de novembro de 2009.

${ }^{5}$ A primeira versão do Código Mundial Antidopagem, foi aprovada em outubro de 2013 e entrou em vigor em $1^{\circ}$ de Janeiro de 2004. Posteriormente, em novembro de 2007 e por ocasião da Terceira Conferência Mundial sobre a Dopagem no Esporte, realizada em Madrid, foi objeto de revisão, sendo aprovadas pelo Conselho da Fundação da AMA as emendas à versão original em 17 de novembro de 2007, as quais entraram em vigor em $1^{\circ}$ de janeiro de 2009. Atualmente a WADA já formulou a terceira versão do Código que entrou em vigor em $1^{\circ}$ de janeiro de 2015, fruto da Quarta Conferência Mundial sobre Dopagem no esporte, que ocorreu na cidade de Johannesburgo durante os dias 12-15 de novembro de 2013. Cfr. ATIENZA MACÍAS, Elena - El tratamiento jurídico del dopaje: de la Declaración de Lausana de 1999 a la Ley Orgánica de 2013. Un repaso obligado con ocasión de las novedades implantadas en el terreno de juego nacional e internacional. Revista Española de Derecho Deportivo. 32 (2013) 57-82.

${ }^{6}$ Cfr. ATIENZA MACíAs, Elena - 2015 WADA code comes into effect: significant changes in the Spanish legal arena. The International Sports Law Journal (ISLJ). 15:1 (2015) 49-54.
} 
Orgânica 03/3013, de 20 de julho, para a Proteção da Saúde do Desportista e da Luta contra a Dopagem na Atividade Desportiva (LO 3/2013) ${ }^{7}$ - que derrogaria a sua lei orgânica predecessora de 2006. Um feito especialmente relevante pela singularidade do marco jurídico que traz em seu bojo um preceito: proteção integral da saúde do desportista, para além da problemática da dopagem. Seguindo esses argumentos, a presente lei excede em muito uma simples norma de antidopagem.

Nesse sentido, a intenção do legislador espanhol foi a de incluir um potente sistema de proteção da saúde para quem realize qualquer atividade desportiva. Em linhas gerais, a nova lei trata de diferenciar as medidas que afetam os desportistas de forma genérica, sendo estas medidas positivas de prevenção dos riscos para a saúde associados a práticas desportivas e medidas específicas de luta contra a dopagem, de âmbito mais restrito.

Com efeito, este elenco normativo vai mais além e a dopagem não é mais o elemento primordial do mesmo e, sem prejuízo da importância que indiscutivelmente tem a regulação sobre esse fenômeno, a nova lei trata de configurá-lo, insiste-se, como um elemento a mais dentro do sistema de proteção da saúde dos desportistas. Assim, a reforma planejada há inserido um avanço na proteção da saúde dos desportistas.

De especial consideração é o fato de que a saúde do desportista é a espinha dorsal da lei e a dopagem se revela como a "parte patológica" desse sistema, uma "mancha" que deve ser erradicada ${ }^{8}$, pois afeta a proteção da saúde dos desportistas, o fair play do esporte, a igualdade de condições na competição e a própria dimensão ética deste (sendo estes os três pilares desse regime antidopagem). Também, por esta razão, se pode dizer que a prevenção e o controle da dopagem são tratados na lei como um elemento componente de uma realidade muito mais ampla, que é a proteção da saúde do desportista.

Entre as novidades organizativas que se estabeleceu com a regulação de 2013, a nova "Agência Espanhola de Proteção da Saúde no Esporte" (AEPSAD) - que substitui a emblemática Agência Estatal Antidopagem (AEA) - se configura atualmente como um órgão público independente e encarregado da proteção da saúde e dos desportistas, com competência em matéria de prevenção, repressão e investigação. Assim mesmo, uma

\footnotetext{
${ }^{7}$ O texto na íntegra pode ser consultado no Boletim Oficial do Estado (BOE), núm. 148, de 21 de junho de 2013. Disponível em: http://www.boe.es/boe/dias/2013/06/21/pdfs/BOE-A-2013-6732.pdf [Última consulta: 15 de julho de 2015].

${ }^{8}$ Nas palavras de Ana MuÑoz MERINO, a então Diretora da Agência Estatal Antidopagem (AEA). Cfr. MuÑOZ MERINO, Ana - Presente y futuro de la lucha antidopaje en España. Conferencia pronunciada en el Seminario de la Agencia Noruega Antidopaje: "Doping in elite sports. What can we learn from major international doping cases?”, Oslo, Noruega, 10 de junho de 2013. Disponível em:

http://www.aepsad.gob.es/dms/microsites/aepsad/actualidad/noticias/2013/junio/20130610-presente-y-futurolucha-antidopaje/presente $\% 20$ y 20futuro\%20lucha\%20antidopaje\%20oslo\%202013\%20espa\%C3\%B1ol.pdf [Última consulta: 15 de julho de 2015].
} 
novidade que aqui interessa é a de que o "Laboratório de Controle de Dopagem" se tornou uma área autônoma e independente da Direção da Agência, não formando parte de seus órgãos de governo e gerindo autonomamente os laboratórios, assunto ao qual se dedicará atenção nos itens posteriores.

\section{Os complementos alimentares como substâncias dopantes?}

\subsection{Esboço do problema}

Os complementos alimentares (também denominados "suplementos dietéticos" ou “suplementos alimentícios") são definidos legalmente pelo Decreto Real 1487/2009, de 26 de setembro, relativo aos complementos alimentares ${ }^{9}$, como produtos alimentícios consistentes em fontes concentradas de nutrientes na dieta normal. À luz do Real Decreto mencionado, existe uma ampla gama de nutrientes e outros elementos que podem estar presentes nos complementos alimentares, incluindo, entre outros as vitaminas, aminoácidos, ácidos graxos essenciais, fibras, plantas e extratos de ervas.

Não há dúvida de o desportista deve ter uma especial precaução ${ }^{10}$ quando consome complementos alimentares valorando, com a ajuda de um profissional da área da nutrição, a necessidade de seu consumo. Se se determina que estes sejam necessários, se deve evitar a compra de produtos etiquetados em língua estrangeira, comprados através da internet e sem conhecer sua origem ou confiabilidade.

Uma questão que se liga a anterior é o fato de que grande parte das substâncias proibidas no esporte se encontra em medicamentos que chegam ao desportista por meio dos mercados clandestinos. Nesse contexto é de se ressaltar o "Convênio do Conselho da Europa sobre falsificação de produtos médicos e delitos similares que representem uma ameaça para a saúde pública" (Convênio MEDICRIME ${ }^{11}$ ).

A partir desse documento, o Conselho da Europa criou, em dezembro de 2010, a chamada Convenção MEDICRIME, que estabelece pela primeira vez um tratado internacional, em matéria penal, sobre falsificação de produtos médicos e delitos similares

\footnotetext{
${ }^{9}$ Foi por meio dessa norma que se incorporou ao ordenamento jurídico interno a Directiva 2002/46/CE del Parlamento Europeo y del Consejo, de 10 de junio de 2002, relativa a la aproximación de las legislaciones de los Estados miembros en materia de complementos alimenticios (DO L 183 de 12.7.2002). Disponible en: http://eur-lex.europa.eu/legal-content/ES/TXT/?uri=celex:32002L0046 [Última consulta: 15 de julho de 2015] ${ }^{10}$ Sobre o princípio da precaução no âmbito do esporte trata PATEL, Seema - Exploring Key Themes. Safety: the precautionary principle. In: Inclusion and Exclusion in Competitive Sport. Socio-Legal and Regulatory Perspectives. Nueva York: Routledge, 2015, pp. 155-172.

${ }^{11}$ Para consultar: https://www.edqm.eu/site/the-medicrime-convention-1470.html [Última consulta: 15 de julho de 2015]
} 
que representem uma ameaça para a saúde pública. A Espanha foi o segundo país a ratificar esse convênio. O MEDICRIME confere aos Estados uma ferramenta muito potente para combater esse estigma: a introdução de padrões mínimos comuns na área penal e processual penal em todos os países subscritores do tratado. Também, estabelece pontos de contato nos Sistemas Nacionais de Saúde, nos laboratórios de referência para a polícia e autoridades aduaneiras, objetivando assegurar os intercâmbio de informações e a cooperação transfronteiriça. Com isso, a ratificação deste convênio e sua entrada em vigor significa um passo importante na persecução do tráfico internacional de produtos médicos, incluindo-se aí as substâncias e métodos proibidos no esporte.

Recentemente o diretor da AEPSAD (Enrique Gómez Bastida) e a Diretora da Agência Espanhola de Medicamentos e produtos Sanitários (Belén Crespo SánchesEznarriaga), o AEMPS, firmaram um convênio marco de colaboração - Convênio de Colaboração entre a AEPSAD e a Agência espanhola de Medicamentos e Produtos Sanitários, Madrid, Espanha, 26 de maio de $2015^{12}$ - cujo objetivo é articular linhas de cooperação, colaboração, coordenação e comunicação entre ambos em matéria de proteção da saúde dos desportistas, mediante a prevenção e luta contra a dopagem no esporte. Nesse sentido, a AEPSAD vem detectando que algumas infrações à normativa antidopagem derivam, entre outros, da proliferação de medicamentos ilegais que contém substâncias cujo consumo possa ocasionar um risco para a saúde dos desportistas, incluindo-se as sustâncias proibidas no esporte ou a aquisição de medicamentos fora dos canais legalmente estabelecidos para sua custódia, conservação e aplicação ${ }^{13}$.

Ao se chegar a este ponto, se pode perguntar: os complementos alimentares tem o mesmo controle que os medicamentos? A resposta, como era de se supor, é negativa, tendo em vista que esses não são considerados medicamentos e permanecem em um "limbo", onde a possibilidade de controle e regulação permanece bem pequena. Logo, os complementos alimentícios não possuem a condição de medicamentos e não estão sujeitos a controles próprios da indústria farmacêutica, pelo que, podem apresentar em sua composição contaminações por substâncias não declaradas e que sejam proibidas no esporte. Na prática,

\footnotetext{
${ }^{12}$ Informação disponível na página da internet da AEPSAD:

http://www.mecd.gob.es/aepsad/en/actualidad/2013/noviembre/20131121-aepsad-convencion-medicrime.html [Última consulta: 15 de julho de 2015].

${ }^{13}$ A doutrina aponta o perigo das novas tecnologias enquanto canais para a comercialização e distribuição de productos dopantes, v. JORDÁ SANZ, Carmen; GIMÉNEZ-SALINAS FRAMIS, Andrea - El tráfico ilícito de medicamentos: un nuevo mercado ilegal para el crimen organizado. Revista Electrónica de Ciencia Penal y Criminología. 17:Junho (2015) se pode consultar em: http://criminet.ugr.es/recpc/17/recpc17-10.pdf y MORENO LisO, Lourdes; ViÑUELAS ZAHÑINOS, M ${ }^{\mathrm{a}}$ Teresa - La venta de medicamentos dopantes en Internet. In: BoSCH CAPdevila, Esteve; Franquet Sugrañes, María Teresa (Coords.), Dopaje, fraude y abuso en el deporte. Barcelona: Ed. Bosch, 2007, pp. 93-105.
} 
ocorre que uma grande porcentagem de resultados positivos em controle de dopagem se deve à presença ou contaminação de complementos alimentares com substâncias incluídas na lista de substâncias e métodos proibidos no esporte ${ }^{14}$.

O problema se acentua no momento um desportista pode ser punido quando de um controle positivo devido a uma substância proibida que esteja presente em um complemento. Assim, com relação ao regime penal e a luta conta a dopagem, a AEPSAD adverte que a detecção da presença de uma substância proibida, de seus metabólitos ou marcadores nas amostras físicas de um desportista é tipificado como infração muito grave e apenável com dois anos de retirada da licença federativa, de acordo com o artigo 22.1., da LO 3/2013. Nesses casos, alegar o desconhecimento da presença, seja por simplesmente desconhecimento da composição ou por uma deficiência de descrição de substâncias na rotulagem, não é considerado uma justificativa válida.

Entretanto, é importe ressaltar o dever de informar que os fabricantes de complementos alimentares possuem, pois o desportista é, também, um consumidor e como tal é considerado vulnerável por ter facilmente limitada a sua livre manifestação de vontade. Isto é especialmente verdade no que se refere à escolha de suas prioridades e necessidades, tendose em vista todos os procedimentos, mecanismos, métodos e técnicas utilizados pelos fornecedores para, mesmo indiretamente, fomentar, manter, desenvolver e garantir a circulação de seus produtos e serviços.

Em virtude disso, há um consenso no mundo ocidental sobre a vulnerabilidade do consumidor, já tendo a ONU se pronunciado sobre este assunto, na Resolução 29/248 de 10.04.85, a qual reconhece que os consumidores se deparam com vários desequilíbrios, o que conflita com o direito de acesso a produtos e serviços seguros e inofensivos. Em grande medida, contudo, a ausência de eventual regulamentação sobre rotulagem não desobrigaria o fornecedor de prestar a mais completa e adequada informação sobre os ingredientes dos produtos que comercializa, tendo em vista o princípio da boa-fé objetiva (transparência, lealdade e informação) e da vulnerabilidade ${ }^{15}$.

\footnotetext{
${ }^{14} \mathrm{Na}$ Espanha o documento sobre essa materia, que até esta data se encontra vigente, foi incorporado ao ordenamento espanhol por meio da Resolución de 18 de diciembre de 2014, de la Presidencia del Consejo Superior de Deportes, por la que se aprueba la lista de sustancias y métodos prohibidos en el deporte. BOE Número 315 de 30 de dezembro de 2014. Disponível em: http://www.boe.es/boe/dias/2014/12/30/pdfs/BOE-A2014-13615.pdf, que, entrando em vigor em $1^{\circ}$ de janeiro de 2015, vigerá até 31 de dezembro de 2015.

${ }^{15}$ MYSZCZUK, Ana Paula; GLITZ, Frederico - Transgênicos e vulnerabilidade no Direito do Consumidor: o direito de ser informado. Revista de Direito Público. 5:3 (2010) 01-16.
} 


\subsection{Instrumentos normativos na esfera internacional ou europeia}

No contexto da repressão a dopagem um passo transcendental teve lugar em 2005, durante a $33^{\mathrm{a}}$ Conferência Geral da UNESCO, celebrada em Paris, quando foi aprovada a Convenção Internacional contra a Dopagem no Esporte ${ }^{16}$, em 19 de outubro, cuja ratificação por parte dos países signatários tornou possível uma harmonização normativa e a efetiva obrigatoriedade do Código Mundial Antidopagem nos territórios dos mesmos. Pois bem, a convenção já alertou sobre essa problemática e sinalizou que os governos gozam de certo grau de flexibilidade sobre que tipo de regulação adotará para dar efeito à convenção, seja mediante uma legislação, regulamentação, política ou prática administrativa. Não obstante, os governos signatários (entre esses a Espanha, que ratificou a convenção em 25 de outubro de 2006) estão obrigados a adotar medidas específicas para:

"Incentivar os produtores e distribuidores de suplementos nutricionais para que fixem as "práticas mais idôneas" na rotulagem, comercialização e distribuição de produtos que posam conter substâncias proibidas”.

No panorama normativo europeu se destaca o Regimento (EU) n. $^{\circ} 1169 / 2011$ do Parlamento Europeu e do Conselho sobre a Informação Alimentaria Facilitada ao Consumidor ${ }^{17}$. Conhecido como "Regulamento IAC", este entrou em vigor em 12 de dezembro de 2011, sendo aplicável a partir de 13 de dezembro de 2014, com exceção das disposições relativas à informação nutricional, que serão aplicáveis a partir de 13 de dezembro de 2016. O Regulamento obriga a rotulagem dos complementos alimentares "de maneira clara e compreensível para ajudar os consumidores que desejem tomar suas decisões a respeito da alimentação e dieta com maior conhecimento de causa". Além disso, "deve indicar-se o país de origem e o lugar de procedência de um alimento sempre que a falta de tal indicação possa induzir os consumidores a engano acerca do verdadeiro país de origem ou lugar de procedência de dito produto".

Ainda, na Agência Antidopagem dos Estados Unidos (conhecida como USADA) se aprovou uma regulação de grande importância nesse setor: o Designer Anabolic Steriod Control Act, de dezembro de $2014^{18}$, que tem por objetivo prevenir que esteroides possam ser

\footnotetext{
${ }^{16}$ Disponível em:

http://portal.unesco.org/es/ev.php-URL_ID=31037\&URL_DO=DO_TOPIC\&URL_SECTION=201.html [Última consulta: 15 de julho de 2015].

${ }^{17}$ DOUE núm. 304, de 22 de novembro de 2011, pp. 18 a 63 (46 págs.).

${ }^{18}$ H.R.4771 - Designer Anabolic Steroid Control Act of 2014, 113th Congress (2013-2014). Disponível em: https://www.congress.gov/bill/113th-congress/house-bill/4771/text?overview=closed [Última consulta: 15 de julho de 2015].
} 
comercializados como complementos alimentares ou distribuídos a partir de uma rotulagem falsa. A aprovação desta regra representa um passo importante para ajudar na proteção dos desportistas, em todos os níveis; e aos consumidores das empresas que vendem esteroides que estejam mascarados como complementos. Como parte da missão da USADA em prol dos desportistas "limpos" de dopagem, a Agência Americana trabalha para ajudar os desportistas à entender os riscos associados ao uso de complementos alimentares ${ }^{19}$.

\subsection{A posição da Agência Espanhola de Proteção da Saúde no Esporte (AEPSAD)}

A AEPSAD alerta os desportista das possíveis consequências, tanto para sua saúde como ante a eventuais sansões desportivas, o que a falta de vigilância na compra e no consumo de complementos alimentares podem ocasionar. Dessa maneira os desportistas devem manter uma conduta ativa de luta contra a dopagem no esporte e assegurar-se de que nenhuma substância proibida seja introduzida em seu organismo, sendo responsáveis quando se detecte sua presença ${ }^{20}$.

Entre os mecanismos que se idealizaram e que estão respaldados pela AEPSAD destaca-se o "Programa de certificação de ausência de substâncias proibidas", chamado "Informed Sport". O grupo científico internacional LGC (grupo que liderada o referido programa) tem trabalhado com a Agência com o intuito de aumentar o conhecimento dos riscos relacionados com a dopagem involuntária que pode derivar de produtos contaminados com substâncias proibidas pela AMA.

A AEPSAD assessora pró-ativamente os desportistas e organizadores de esporte espanhóis sobre o problema da dopagem involuntária e remete-se ao Informed Sport como a solução mais eficaz e amplamente reconhecida para minimizar o risco. O Informed Sport foi criado pela empresa britânica LGC, que desenvolveu esse programa de provas e certificações de complementos alimentares juntamente com a Organização Nacional Antidopagem (como UKAD, do Reino Unido ou, o NADA, da Alemanha), o qual permite ao desportista ter acesso a uma compra segura de complementos.

Na página da internet ${ }^{21}$ criada para isso, o desportista tem a sua disposição uma

\footnotetext{
${ }^{19}$ A partir dessa nova normativa se instaurou o Projeto: www.Supplement411.org

${ }^{20}$ Recentemente a AEPSAD se referiu a esse assunto com a pergunta: Suplementos Nutricionales. ¿Puerta de entrada al dopaje?. Disponível em: http://www.aepsad.gob.es/aepsad/educacion/divulgacion-cientifica/cienciassociales/2013/20130428-suplementos-nutricionales.html [Última consulta: 15 de julho de 2015].

${ }^{21}$ Informed Sport avalia o processo de produção e certificação da ausência de contaminações por substâncias proibidas no esporte, por lotes de fabricação, garantindo a segurança do produto e de que o complemento consumido pelo desportista forma parte de um lote analisado e certificado como "livre de substâncias dopantes".
} 
relação de fabricantes, produtos e lotes, com confirmação de ausência de substâncias proibidas no esporte, o que permite fazer a escolha correta. Além de apresentar à AEPSAD material educativo em língua espanhola dirigido aos interessados, a LGC apresentou seu programa aos líderes da indústria espanhola de complementos desportivos, oferecendo seu assessoramento em matéria de garantia de qualidade.

Com isso se busca disponibilizar um sistema de rastreabilidade, tendo em vista o sistema de identidade preservada (IP). Neste cenário, a indústria de complementos alimentares para desportistas deverá adaptar-se a um controle rigoroso dos processos, consubstanciado na certificação, quanto à garantia da inocuidade e da preservação das qualidades nutritivas dos complementos alimentares produzidos para os consumidores. A rastreabilidade atende diversas funções. De um lado, é a forma de simplificar a localização de problemas, reduzindo o volume de devolução de produtos. Por outro lado, a determinação das responsabilidades dos agentes sobre as condições de conformidade dos produtos em cada etapa do seu percurso na cadeia produtiva é outra das funções da rastreabilidade. Com a rastreabilidade é possível seguir o processo inverso e descobrir qual a matéria-prima ou componente foi utilizado na fabricação do produto. A produção no campo, transporte, armazenamento e processamento de matérias-primas básicas são fontes potenciais de degradação da qualidade dos produtos em termos das suas características. Assim, as operações de manuseio e embalagem, transporte e estocagem são pontos críticos de controle de qualidade dos complementos alimentares, em suas diversas etapas de processamento ${ }^{22}$. Isso é de fundamental importância, quando a possibilidade de punição do desportista é uma realidade.

\subsubsection{Laboratório de Controle de Dopagem}

$\mathrm{Na}$ medida em que os complementos alimentares possam estar contaminados com substâncias não indicadas na rotulagem e que possam resultar em positivo num controle antidopagem (principalmente para esteroides), o COI (Comitê Olímpico Internacional) e a Organização Mundial da Saúde (OMS) recomendam estender os controles, também, aos complementos alimentares. Esses controles se baseiam em análises realizadas em amostras biológicas obtidas de desportistas que tenham participado ou vão participar de uma

\footnotetext{
Na página da internet (www.Informed-Sport.com) o desportista tem a sua disposição uma relação de fabricantes, produtos e lotes dos complementos com confirmação de ausência de substâncias proibidas no esporte e que lhe permitirá fazer a escolha correta.

${ }^{22}$ Ver: MYSZCZUK. Ana Paula; GLITZ, Frederico; WANSCHEER, Clarissa - Segurança alimentar e consumo: rastreabilidade e certificação de grãos GM e NON-GM. Revista Cesumar - Ciências Humanas e Sociais Aplicadas. 15:1 (2010) 125-145.
} 
competição desportiva.

A importância que adquire, nesse contexto, o laboratório de Controle de Dopagem está no fato de que as amostras somente podem analisadas em laboratórios de controle de dopagem certificados pela AMA, pelo que devem cumprir uma série de requisitos quanto as suas instalações, pessoal, manual de qualidade e procedimentos técnicos e protocolos de segurança. Na Espanha estes requisitos se encontram reunidos no decreto Real n. ${ }^{\circ}$ 1744/2011, de 25 de novembro ${ }^{23}$.

Esta instituição se encontra anexa organicamente à AEPSAD e, de acordo com o estabelecido na normativa correspondente ${ }^{24}$, atua em plena independência funcional com a finalidade de garantir a confiança em sua capacidade, confiança e imparcialidade. É oportuno indicar que o laboratório é responsável pelas seguintes tarefas:

a) A realização e execução das provas analíticas correspondentes, assim como as complementares para o controle das práticas de dopagem, com a finalidade de comprovar a presença de alguma substância proibida, de algum de seus metabólidos, algum de seus marcadores ou a utilização de algum método não regulamentado. Essa atuação deve tender a ser desenvolvida conforme o estabelecido no disposto nos Padrões Internacionais de Laboratórios aprovados pela AMA e nas normas procedimentais que efetivamente decorram da $\mathrm{LO}^{\circ}$ 3/2013.

b) A elaboração de estatísticas de controle de dopagem, tanto de amostras nacionais como internacionais, ou de outras entidades de âmbito privado, que possam encomendar procedimentos analíticos de controle de dopagem, com pleno respeito à normativa sobre proteção de dados.

c) Qualquer outra que se determine para os Laboratórios de Controle de Dopagem homologados pela AMA.

Por fim, é conveniente se perguntar se existem complementos alimentares avalizados pelos laboratórios antidopagem. A partir desta perspectiva, cabe advertir que os Laboratórios de Controle de Dopagem acreditados pela AMA não analisarão preparados comerciais, a não ser por prévia petição de uma organização antidopagem, como parte de uma investigação. Os laboratórios oficiais da AMA em nenhum caso fornecerão resultados, documentação ou

\footnotetext{
${ }^{23}$ Norma que modifica o Decreto Real 641/2009, de 17 de abril, que regula os processos de controle de dopagem, os laboratórios de análises autorizados e estabelece medidas complementares de prevenção da dopagem e de proteção da saúde no esporte. BOE Núm. 308 de 23 de Dezembro de 2011. Disponível em: http://www.boe.es/diario_boe/txt.php?id=BOE-A-2011-20028 [Última consulta: 15 de julhoo de 2015].

${ }^{24}$ Artigo 15 do Decreto Real n. ${ }^{\circ} 461 / 2015$, de 05 de junho, por meio do qual se aprova o Estatuto da AEPSAD.
} 
avisos que avaliem o produto.

\section{O problema da contaminação por meio de complementos alimentares: o polêmico "Caso Contador"}

Em 06 de Fevereiro de 2012 o Tribunal de Arbitragem do Esporte (TAS), com sede em Lausanne, sentenciou sobre o caso de dopagem que envolvia o ciclista espanhol Alberto Contador $^{25}$. No denso laudo o mesmo é condenado a pagar uma multa de $€ 2.485 .000$ para a União Ciclística Internacional (UCI), além de cumprir uma pena desportiva de dois anos de suspensão. O ciclista foi testado positivo em ambas as amostras, A e B, de um teste de dopagem levado a cabo em setembro de 2010, durante o Tour de France. Foram encontrados em seu corpo, exatamente, 50 picogramos de uma substância chamada "clembuterol", proibida tanto pela lista da Agência Mundial Antidopagem (WADA), como pela lista da $\mathrm{UCI}^{26}$.

Foi imposta a esse desportista uma sansão de suspensão por dois anos e a perda do título do Tour de France de 2010 - no qual foi considerado positivo para a substância clembuterol - e todas as demais vitórias conseguidas a partir de 25 de janeiro, dies a quo estabelecido para o período da pena, por considerar que o teste que o positivou para clembuterol decorreu, mais provavelmente, da ingestão de um complemento alimentar contaminado, do que pela ingestão de carne contaminada, que foi alegado pelo atleta. A hipótese dos complementos alimentares contaminados foi considerada na sentença do Tribunal Arbitral do Esporte como causa mais provável, mesmo que este não pudesse estabelecer expressamente qual fato determinou a contaminação e detecção da substância ${ }^{27}$.

\footnotetext{
${ }^{25}$ COURT OF ARBITRATION FOR SPORT, 2012, CAS 2011/A/2384 UCI v. Alberto Contador Velasco \& RFEC CAS 2011/A/2386 WADA v. Alberto Contador Velasco \& RFEC. Disponível em: http://www.tascas.org/fileadmin/user_upload/Bulletin202012_1.pdf

${ }^{26}$ Para o professor LóPEZ NiCOLÁs, do departamento de Bioquímica e Biologia Molecular da Universidade de Murcia, este caso possui inúmeros interrogações muito arrojadas: Pode uma quantidade ridícula como 50 picogramos de uma substância provocar algum efeito sobre o organismo humano? Que benefícios/prejuízos pode ter um desportista que consome clembuteol? É possível detectar a referida quantidade em uma análise sem possibilidade de erro? Até que ponto pode-se assegurar que não é uma quantidade gerada pelo próprio organismo do atleta? Realmente se pode dar positivo pela ingestão de alimentos procedente de animais que apresentam clembuterol em seu organismo? O clembuterol serve ou não para mascarar outras substâncias dopantes? V. LÓPEZ NiCOLÁs, José Manuel, "¿Son fiables las determinaciones analíticas llevadas a cabo en el `Caso Contador'?", SCIENTIA, 20 de julho de 2012. Disponível em: http://scientiablog.com/2012/07/20/son-fiableslas-determinaciones-analiticas-llevadas-a-cabo-en-el-caso-contador/

${ }^{27}$ Com efeito, o Dr. Jean-Pierre de Mondenard não duvidou em afirmar que se há uma tese verdadeiramente improvável é do complemento alimentares contaminado, recordando que esse gênero de complemento se consome cotidianamente durante vários dias e não somente uma vez. E, acrescenta: "En el caso del Tour de Francia, en razón de las exigencias energéticas de la carrera - 6.000 a 7.000 kilocalorías quemadas en cada etapa- los complementos alimenticios están cotidianamente en el menú de la cena del gigante de la ruta, salvo
} 
O clembuterol que um fármaco que, comprovadamente, pode melhorar o rendimento desportivo. Em um primeiro momento, o Comitê de Competição absolveu o ciclista por ausência de culpa ou negligência - não foi possível declarar-lhe responsável por violar uma norma antidopagem, em virtude do artigo 296 do regulamento Antidopagem da UCI, que estabelece a necessidade de voluntariedade na ingestão de substâncias proibidas.

O TAS utilizou para resolver a questão da "teoria do complemento alimentar". Destaque-se: o Caso Contador vem sendo considerado como paradigmático do império da responsabilidade objetiva em matéria disciplinar desportiva ${ }^{28}$. Com essa nova teoria o que o TAS estabelece é que, ainda que não se possa determinar como a substância proibida chegou até o organismo do desportista, a maneira mais provável é que tenha sido por meio de um complemento alimentar, de tal modo que se o desportista não puder demonstrar que tenha sido plenamente diligente, haverá justificativa para sua condenação, em virtude da rigorosa aplicação do princípio de responsabilidade objetiva ${ }^{29}$. Esse caso é paradigmático a partir de que o princípio in dubio pro reo ${ }^{30}$, característico em todos os ramos do Direito, cai, em favor do princípio da responsabilidade objetiva, invertendo-se o ônus da prova ${ }^{31}$.

que el madrileño no ha sido controlado positivo más que una vez y que, si hay contaminación, es que lo está la caja entera!". Cfr. MondENARD, Jean-Pierre de - Affaire Contador: 'l'hypothèse du TAS n'est pas crédible'. Le Monde, 15 de Fevereiro de 2012. Disponível em: http://www.lemonde.fr/sport/article/2012/02/15/affairecontador-1-hypothese-du-tas-n-est-pas-credible_1643452 3242.html. A situação descrita não é nova, pois aconteceu algo semelhante na questão da nadadora americana Jessica Hardy. Sobre o "Caso Hardy" se manifestou RodRíGUEz GARCÍA, José em "La AMA y su reglamentación”. In: OLMEDO, Alberto Palomar. El dopaje en el deporte (2013) 110-111. Nesse caso a AMA deu por certo que é possível que se detecte um positivo por contaminação de complementos alimentares, por mais confiável que seja a fonte onde são adquiridos.

${ }^{28}$ AMORÓs MARTíneZ, Agustín - El caso Contador: una lectura reposada a la luz del borrador del CSD sobre el proyecto de ley orgánica de lucha contra el dopaje, op. cit., pp. 469-476; com especial interesse interesse em: Valoración de la prueba vs. Confirguración del tipo de la infracción de dopaje; presunción de inocencia vs. Principio de responsabilidad objetiva; DESCALZO GONZÁLEZ, Antonio - Alberto Contador, el caso y el marco. Actualidad Jurídica Aranzadi. 815 (2011) 2; JUANES PECES, Ángel - Aplicación de los principios del Derecho sancionador al ámbito deportivo: caso Contador. Actualidad Jurídica Aranzadi. 817 (2011) 5 y FRIDMAN, Saul Contador, cows and strict liability. Sports Law eJournal. 2012. Disponível em:

http://epublications.bond.edu.au/cgi/viewcontent.cgi?article=1015\&context=slej [Última consulta: 15 de julho de 2015].

${ }^{29}$ Expõe Tomás-Ramón FERNÁNDEZ, que o regime jurídico estabelecido na LO 3/2013 resulta inteiramente alheio às tradições espanholas, em virtude de que, a partir da ratificação d Convenção de 2005 e da consequente admissão dos princípios básicos do Código Mundial Antidopagem, se adequou a responsabilidade disciplinar ao tipo de responsabilidade que o Código define como objetiva, isto é, pelo simples resultado, que se constrói a partir da imposição aos desportistas de um dever impossível de se cumprir, que é o de assegurar-se de que nenhuma substância proibida se introduza em seu organismo. Cfr. FERNÁNDEZ, Tomás-Ramón - De la Sentencia 'Heras' a la Sentencia 'Contador'. Presente y futuro de la justicia deportiva. Revista de Administración Pública. 191 (2013) 299-300. No mesmo sentido v. AlONSO MARTínEZ, Rafael - Falsos mitos sobre el caso Contador. Derecho deportivo en línea. 16 (2011) disponível em: http://www.dd-el.com/products/n\%C2\%BA-16$\% 28$ septiembre-2010-marzo-2011\%29/

${ }^{30}$ CASTAÑos DomíngueZ, Delia - La ausencia del principio in dubio pro reo en materia de dopaje. Iusport. 10 de maio de 2012, disponível em: http://iusport.com/not/668/la-ausencia-del-principio-in-dubio-pro-reo-enmateria-de-dopaje

${ }^{31}$ Merece ser consultada a tese de doutorado de ÁlvareZ VIEJO, Julia Amada - Estado de Derecho y Lucha contra el Dopaje. Oviedo: Universidade de Oviedo, 2013, pp. 546-557, que apresenta uma interessante 
De toda maneira, não se pode falar, de forma pura, de uma autêntica responsabilidade objetiva (melhor uma "quase objetiva"32) uma vez que não se impõe forma automática de responsabilidade pelo mero resultado ${ }^{33}$, admitindo-se a hipótese de redução ou mesmo absolvição se o desportista denunciado conseguir provar que não houve dolo, negligência de sua parte ${ }^{34}$ ou, pelo menos, que não tenha culpa significativa, devendo demonstrar de que maneira a substância proibida entrou em seu organismo ${ }^{35}$.

Em face ao caso do ciclista Contador, se destaca o entendimento diferente no caso do australiano Michael Rogers. Nesse caso, Rogers alegou que ingeriu carne contaminada com clembuterol, sendo absolvido pela União Ciclista Internacional (UCI). O australiano havia testado positivo no laboratório de Tókio, em um controle efetuado em 20 de Outubro de 2013. O mesmo havia ganho a Copa do Japão e foi suspenso preventivamente pela UCI. Entretanto, o campeão do mundo no contrarrelógio alegou como causa a adulteração da carne que comeu na China durante sua participação na Volta de Pequim. A UCI, depois de consultar a AMA

comparação entre os Casos Hardy, Gasquet, Cielo e o Caso Contador, como emblemáticos na aplicação estrita do princípio de responsabilidade objetiva por parte do Tribunal de arbitragem Desportivo. V. também RATHGEBER, Geoffrey - Gold medalist to cheater?: improving the world's fight against doping in the wake of Fina v. Cielo. Emory International Law Review. $26: 2$ (2012) 1120-1156 y VALERO, Alfonso - 'Caso Gasquet': tus besos son mi droga: Análisis del laudo del TAS 2009/A/1926 y 1930. ITF-WADA vs Richard Gasquet, Revista Aranzadi de Derecho de Deporte y Entretenimiento. 29 (2010) 469-474.

${ }^{32}$ De LA IGLESIA PRADOS, Eduardo - Derecho disciplinario deportivo y fútbol profesional. In: MILLÁN GARRIDO, Antonio (Coordenador) - Estudios jurídicos sobre el fútbol profesional. Madri: Editorial Reus, 2013, Capítulo V: "Cuestiones de interés y principales problemas en la actual configuración pública de la disciplina deportiva" se refere a "Vigencia del principio de culpabilidad para la imposición de sanciones", fazaneo eco com a p. 63 da sentença do "Juzgado Central de lo Contencioso Administrativo" de 31 de Janeiro de 2006 (RJCA 2006, 228).

33 "Algo que sería radicalmente inadmisible desde luego", nas palabras de FERNÁNDEZ, Tomás-Ramón, "La dudosa constitucionalidad del régimen sancionador del dopaje deportivo", Revista Vasca de Administración Pública, 99/100 (2014) 1359, disponível em:

https://www.euskadi.net/r61-

s20001x/es/t59aWar/t59aMostrarFicheroServlet?t59aIdRevista=2\&R01HNoPortal=true\&t59aTipoEjemplar=R\& t59aSeccion $=38 \& \mathrm{t} 59 \mathrm{aContenido}=57 \& \mathrm{t} 59 \mathrm{aCorrelativo}=1 \& \mathrm{t} 59 \mathrm{aVersion}=1 \& \mathrm{t} 59 \mathrm{aNumEjemplar}=99$

${ }^{34}$ RodRíGUEZ TEM Estima mesmo assim, que com esse "novo" marco jurídico estabelecido em 2013 se mantenha uma regime de responsabilidade quase objetiva: "si es que no lo es en realidad". A responsabilidade se articularia da seguinte forma: "se establece una obligación o prohibición genérica y, detectada la existencia de un incumplimiento de la misma mediante la apreciación de unos determinados hechos, corresponde al interesado probar que el incumplimiento no le es achacable. Es decir, se invierte la carga de la prueba, por lo que demostrar la inexistencia de dolo o culpa en un control "positivo" resultará en la práctica casi imposible, la famosa "prueba diabólica". Novamente RoDRíGUEZ TEN, Javier, "El régimen disciplinario del dopaje". In: OLMEDO, Alberto Palomar. El dopaje en el deporte (2013) 420-421.

${ }^{35}$ De acordo com os parágrafos 4 e 5 do artigo 10 do Código: no contexto descrito, alegar uma sabotagem é um recurso que alguns desportistas vêm utilizando, se bem que com poucas perspectivas de êxito até o momento, chamando a atenção o procedimento arbitral levado a cabo no Caso Van Snick, que conseguiu trazer ao tribunal a substância que poderia ser a origem de sua contaminação (Charline Van Snick c. Fédération Internationale de Judo (FIJ), TAS 2014/A/3475, 4 de Julho de 2014). Cfr. LEÓN LLEó, Alfonso - Comentario al laudo del caso TAS 2014/A/3475 Charline Van Snick c. Federación Internacional de Judo (FIJ). Revista Aranzadi de Derecho de Deporte y Entretenimiento. 45 (2014) 487-504; VIRET, Marjolaine; WISNOSKY, Emily - Ain't nobody's fault: Van Snick's cocaine sabotaged sports supplement. The World Anti-Doping Code Commentary Project, The Swiss National Science Foundation - University of Neuchâtel, Neuchâtel, Suiça, 09 de Outubro de 2014. Disponivel em: http://wadc-commentary.com/wp-content/uploads/2014/10/WADC_COMMENTARY_Van$\underline{\text { Snick-Blog.pdf }}$ 
considerou a causa alegada e o absolveu ${ }^{36}$.

\section{Reflexões conclusivas}

Uma grande porcentagem de resultados positivos em controlem de dopagem é devida a existência de contaminação de suplementos alimentares com substâncias incluídas na "Lista de substâncias e métodos proibidos no esporte", circunstância que corresponde à tese da dopagem involuntária, também chamada de não premeditada.

Por isso, um dos fatores de risco principais dos complementos alimentares em relação à positivação de amostras por dopagem é o fato de que muitos desportistas estão utilizando-os com desconhecimento de seus efeitos secundários e das doses recomendadas do produto ${ }^{37}$. Parte do trabalho da AEPSAD - como autoridade competente na Espanha em matéria de proteção da saúde dos desportistas e luta contra a dopagem no esporte - gira em torno da luta contra as substâncias cujo consumo possa impor riscos para a saúde dos desportistas e das pessoas que realizam atividades desportivas. Seu trabalho, portanto, não versa somente em torno da imposição de sansões para infrações das normas antidopagem, mas tem uma função claramente preventiva.

O problema abordado inclui um campo muito extenso, no que se enquadram produtos médicos e complementos legais e ilegais que podem conter substâncias ativas utilizadas tradicionalmente para potencializar o rendimento desportivo e que, em muitos casos, se encontram proibidas no esporte. Portanto, a Agência inclui em suas ocupações a promoção da cooperação nacional e internacional e o intercâmbio de informações entre todos os interessados, se tratem de organismos públicos (autoridades sanitárias, aduaneiras, forças de segurança, etc.) ou de organizações privadas relacionadas a este âmbito.

A AEPSAD assessora pró-ativamente os desportistas e organizações desportivas espanholas sobre o problema da dopagem involuntária. Para esse fim se vale da ferramenta "selos de qualidade", que concede certificação de complementos alimentares desenvolvidos e avaliados em conjunto com a Organização Nacional Antidopagem, permitindo ao desportista efetuar uma compra segura de complementos.

\footnotetext{
${ }^{36}$ De acordo com o escrito por Gleaves, John; Christiansen, Ask Vest - The Curious Cases of Clenbuterol. International Network of Humanistic Doping Research Newsletter, Editorial, June 2014, INHDR, Aarhus University - Department of Public Health, Aarhus, Dinamarca, 2014. Disponível em: http://ph.au.dk/en/aboutthe-department-of-public-health/sections/sektion-for-idraet/forskning/forskningsenheden-sport-ogkropskultur/international-network-of-humanistic-doping-research/newsletters/june-2014/inhdr-editorial-june/ ${ }^{37}$ Cfr. SCHÖNFELDER, Martin - Nutritional Supplements - Creatine. Biomedical Side Effects of Doping. In: SARIKAYA, Hande; PETERS, Christiane; Schulz, Thorsten; SCHÖNFEldER, Martin; MichnA, Horst (Editores), Institute of Public Health Research. Munich: Technische Universität München, 2007, pp. 154-170.
} 
Tudo isso em consonância com os postulados da AMA, para quem a educação dos desportistas e seu entorno é um pilar fundamental na luta contra a dopagem. Em consonância com o Código Mundial Antidopagem de 2015, que enfatiza a necessidade de implementação de programas educativos baseados na prevenção, com o objetivo de que os desportistas e o pessoal de apoio adquiram conhecimentos específicos nas áreas dos riscos relacionados com o uso de complementos alimentares.

\section{Referências:}

Álvarez Viejo, Julia Amada - Estado de Derecho y Lucha contra el Dopaje. Oviedo: Programa de Doutorado, Universidade de Oviedo, Oviedo, Espanha, 2013, pp. 546-557

Amorós MARTínez, Agustín - El caso Contador: una lectura reposada a la luz del borrador del CSD sobre el proyecto de ley orgánica de lucha contra el dopaje. Revista Aranzadi de Derecho de Deporte y Entretenimiento, 36 (2012) 457-492.

ARJONA PÉREZ, David - Suplementos Alimenticios Deportivos, ¿pueden hacer al deportista que `dé positivo'? Alto rendimiento: ciencia deportiva, entrenamiento y fitness. 22 (2011) disponível em: http://altorendimiento.com/nutricion-deportiva-suplementos-2/ [Última consulta: 15 de Julho de 2015]

AtiEnZA MAcÍAs, Elena - 2015 WADA code comes into effect: significant changes in the Spanish legal arena. The International Sports Law Journal (ISLJ). 15:1(2015) 49-54.

AtienZa MacíAs, Elena - El tratamiento jurídico del dopaje: de la Declaración de Lausana de 1999 a la Ley Orgánica de 2013. Un repaso obligado con ocasión de las novedades implantadas en el terreno de juego nacional e internacional. Revista Española de Derecho Deportivo. 32 (2013) pp. 57-82.

CANTERO MARTÍNEZ, Josefa - Política antidopaje y sistema nacional de salud: el nuevo marco de conexiones establecido en la Ley Orgánica 7/2006, de 21 de noviembre. Revista Aranzadi de Derecho de Deporte y Entretenimiento. 23(2008) 54-55.

CASAJÚS MALLÉN, José Antonio - Dopaje, salud y deporte”, Información Terapéutica del 
Sistema Nacional de Salud" 29:1(2005) 7.

Castaños Domínguez, Delia - La ausencia del principio in dubio pro reo en materia de dopaje. Iusport. 10 de maio de 2012, disponível em: http://iusport.com/not/668/la-ausenciadel-principio-in-dubio-pro-reo-en-materia-de-dopaje

COURT OF ARbitration FOR SpORT, 2012. CAS 2011/A/2384. UCI v. Alberto Contador Velasco \& RFEC CAS 2011/A/2386 WADA v. Alberto Contador Velasco \& RFEC. Disponível em: http://www.tas-cas.org/fileadmin/user_upload/Bulletin202012_1.pdf

De LA IGLeSIA PRADOS, Eduardo - Derecho disciplinario deportivo y fútbol profesional. In: Millán GARRIDO, Antonio (Coordenador) - Estudios jurídicos sobre el fútbol profesional. Madri: Editorial Reus, 2013, Capítulo V.

Descalzo GonzÁlez, Antonio - Alberto Contador, el caso y el marco. Actualidad Jurídica Aranzadi. 815 (2011) 2.

FERNÁNDEZ, Tomás-Ramón - De la Sentencia 'Heras’a la Sentencia 'Contador'. Presente y futuro de la justicia deportiva. Revista de Administración Pública. 191 (2013) 299-300. No mesmo sentido v. Alonso MARTínEZ, Rafael - Falsos mitos sobre el caso Contador. Derecho deportivo en línea. 16 (2011) Disponível em: http://www.dd-el.com/products/n\%C2\%BA-16\%28septiembre-2010-marzo-2011\%29/

FRIDMAN, Saul - Contador, cows and strict liability. Sports Law eJournal. 2012. Disponível em: http://epublications.bond.edu.au/cgi/viewcontent.cgi?article=1015\&context=slej [Última consulta: 15 de julho de 2015].

Gleaves, John; Christiansen, Ask Vest - The Curious Cases of Clenbuterol. International Network of Humanistic Doping Research Newsletter, Editorial, June 2014, INHDR, Aarhus University, Department of Public Health, Aarhus, Dinamarca, 2014. Disponível em: http://ph.au.dk/en/about-the-department-of-public-health/sections/sektion-foridraet/forskning/forskningsenheden-sport-og-kropskultur/international-network-ofhumanistic-doping-research/newsletters/june-2014/inhdr-editorial-june/ 
JoRDÁ SANZ, Carmen; GIMÉNEZ-SALINAS FRAMIS, Andrea. El tráfico ilícito de medicamentos: un nuevo mercado ilegal para el crimen organizado. Revista Electrónica de Ciencia Penal y Criminología, 17(2015)

JuANeS PeCeS, Ángel - Aplicación de los principios del Derecho sancionador al ámbito deportivo: caso Contador. Actualidad Jurídica Aranzadi. 817 (2011) 5.

LEÓN LLEÓ, Alfonso - Comentario al laudo del caso TAS 2014/A/3475 Charline Van Snick c. Federación Internacional de Judo (FIJ). Revista Aranzadi de Derecho de Deporte y Entretenimiento. 45 (2014) 487-504

LÓPEZ NiCOLÁS, José Manuel - ¿Son fiables las determinaciones analíticas llevadas a cabo en el 'Caso Contador'?, Scientia. 20 de julho de 2012. Disponível em: http://scientiablog.com/2012/07/20/son-fiables-las-determinaciones-analiticas-llevadas-acabo-en-el-caso-contador/

MondEnARD, Jean-Pierre de - Affaire Contador: 'l'hypothèse du TAS n'est pas crédible'. Le Monde, 15 de fevereiro de 2012. Disponível em: http://www.lemonde.fr/sport/article/2012/02/15/affaire-contador-l-hypothese-du-tas-n-estpas-credible_1643452_3242.html.

MoReno Liso, Lourdes; Viñuelas ZahÑInOS, Ma Teresa - La venta de medicamentos dopantes en Internet. Dopaje, fraude y abuso en el deporte. In: Bosch CAPDEVILA, Esteve; FRAnQuet SugrañEs, María Teresa (Coords.). Barcelona: Ed. Bosch, 2007, pp. 93-105.

MYSZCZUK, Ana Paula; GLITZ, Frederico - Transgênicos e vulnerabilidade no Direito do Consumidor: o direito de ser informado. Revista de Direito Público. 5:3 (2010) 01-16.

MYSZCZUK. Ana Paula; GLITZ, Frederico; WANSCHEER, Clarissa - Segurança alimentar e consumo: rastreabilidade e certificação de grãos GM e NON-GM. Revista Cesumar Ciências Humanas e Sociais Aplicadas. 15:1 (2010) 125-145.

MYSZCZYK, Ana Paula; MEIRELLES, Jussara Maria Leal de - Testes genéticos, Eugenia e contrato do trabalho: Análise à luz da Declaração Universal Dos Direitos Humanos e Do 
Genoma Humano e da Constituição Federal De 1988. In: Anais do XVIII Congresso Nacional do CONPEDI, São Paulo -04, 05, 06 e 07 de novembro de 2009.

RATHGEBER, Geoffrey - Gold medalist to cheater?: improving the world's fight against doping in the wake of Fina v. Cielo. Emory International Law Review. 26:2 (2012) 1120-1156

SCHÖNFELDER, Martin - Nutritional Supplements - Creatine. In: SARIKAYA, Hande; Peters, Christiane; Schulz, Thorsten; SchÖNFELDER, Martin; Michna, Horst (Editores) - Biomedical Side Effects of Doping. Munich: Institute of Public Health Research, Technische Universität München, pp. 154-170.

VAlero, Alfonso - Caso Gasquet: tus besos son mi droga: Análisis del laudo del TAS 2009/A/1926 y 1930. ITF-WADA vs Richard Gasquet. Revista Aranzadi de Derecho de Deporte y Entretenimiento. 29 (2010) 469-474.

VIRET, Marjolaine; WISNOSKY, Emily - Ain't nobody's fault: Van Snick's cocaine sabotaged sports supplement. In: The World Anti-Doping Code Commentary Project. Neuchâtel: University of Neuchâtel, The Swiss National Science Foundation, 2014. Disponivel em: http://wadc-commentary.com/wp-content/uploads/2014/10/WADC_COMMENTARY_Van$\underline{\text { Snick-Blog.pdf }}$

Artigo Recebido a 20 de agosto de 2015 | Aceite a 01 de setembro de 2016 